\title{
A facile low-temperature deposition of Sn-rich tin (II) monosulfide colloid particles
}

\author{
N. S. Kozhevnikova ${ }^{1}$, L. N. Maskaeva ${ }^{2,3}$, E. E. Lekomtseva ${ }^{2}$, L. A. Pasechnik ${ }^{1}$, A. Yu. Chufarov ${ }^{1}$, \\ O. A. Lipina ${ }^{1}$, A. N. Enyashin ${ }^{1}$, V. F. Markov ${ }^{2,3}$ \\ ${ }^{1}$ Institute of Solid State Chemistry of Ural Branch of the Russian Academy of Sciences, Pervomayskaya, 91, \\ Ekaterinburg, 620990, Russia \\ ${ }^{2}$ Ural Federal University named B. N. Yeltsin, Mira, 9, Ekaterinburg, 620002, Russia \\ ${ }^{3}$ Ural Institute of State Fire Service of EMERCOM of Russia, Mira str. 22, 620062, Ekaterinburg \\ kozhevnikova@ihim.uran.ru, larisamaskaeva@yandex.ru, danserkatya13@mail.ru,pasechnik@ihim.uran.ru, \\ circulchufa@gmail.com, lipinaolgaa@yandex.ru, enyashin@ihim.uran.ru, v.f.markov@urfu.ru
}

\begin{abstract}
A novel, eco-friendly and low temperature synthesis of tin (II) monosulfide colloid particles is described. Chemical bath deposition was successfully applied for the deposition of polynanocrystalline $\mathrm{SnS}$ from acidic aqueous solutions. The characterization of the prepared samples was accomplished through elemental analysis, scanning electron microscopy, X-ray powder diffraction, and optical spectroscopy. The composition of tin (II) monosulfide colloids assembled of nanoparticles was found to be Sn-rich. Several simple scenarios for Sn surplus within SnS lattice (Svacancies at S-sublattice, $\mathrm{Sn}$-atoms intercalated between $\mathrm{SnS}$ layers and $\mathrm{Sn}$-doping of S-sites) have been analyzed by means of quantum chemical calculations. The potential application of the $\mathrm{Sn}_{1+x} \mathrm{~S}$ colloid particles in solar cells as absorber material and as photocatalyst was demonstrated by measuring the optical properties.
\end{abstract}

Keywords: tin (II) sulfide, chemical bath deposition, optical band gap, Sn-rich.

Received: 18 September 2020

\section{Introduction}

Metal sulfides represent one of the most important compounds among chalcogenide semiconductor materials due to their unique chemical and electronic properties. $\mathrm{SnS}$ is typically a $p$-type semiconductor with ideal parameters for solar cell absorbers. SnS has attracted much attention in the solar energy conversion due to its near-optimal direct band gap $\left(E_{g} \sim 1.3 \mathrm{eV}\right)$ [1], a high absorption coefficient of $\sim 10^{4}-10^{5} \mathrm{~cm}^{-1}$ [2] for photons with energies greater than the bandgap energy, the high hole densities of $10^{15}-10^{18} \mathrm{~cm}^{-3}$ and mobilities $\sim 90 \mathrm{~cm}^{2} /(\mathrm{Vs})$ [3]. Recently, SnS has also been proven to be an attractive photocatalyst for dye degradation under visible light [4] and for photoelectrochemical splitting of water [5]. The constituent elements, Sn and S, are nontoxic, cost affordable and relatively abundant in nature. Diverse methods for SnS deposition have been developed including vacuum and chemical deposition techniques, namely, vacuum evaporation [6], sputtering [7], vapor transport deposition and epitaxy [8], atomic layer deposition [9], sulfurization of Sn metal films [10], chemical spray pyrolysis [1,11], electrochemical deposition [3,12] and bath deposition $[13,14]$. Though, these numerous approaches are capable for producing thin film materials only.

Recently, the synthesis of SnS in the form of nanocrystals and quantum dots through a single-source precursor route has attracted much attention because of its potential advantages and possibility to tune the size, size distribution, and morphologies of the powder products by controlling the reaction conditions [15]. The precursors employed are usually metal complexes prepared from a Sn salt and ligands in organic media. In the present work, colloid nanoparticles of tin (II) monosulfide have been grown by the chemical bath deposition (CBD) technique. CBD is a solution-based technique providing simple and low-cost pathway to produce both uniform, adherent, reproducible large area thin films and nanostructured powders. CBD is based on the reaction between metal salt and sulfur agent in aqueous solutions. The structural and optical properties of CBD-deposited SnS colloid particles have been studied with the objective to establish the optimum parameters for forming single phase nanostructured SnS for application as a photo-absorber layer in solar cells and in natural sunlight-driven photocatalytic processes.

\section{Experimental}

\subsection{Synthesis and characterization}

The nanostructured SnS colloid particles were precipitated by chemical bath deposition. The SnS-1, SnS-2, SnS-3 and SnS-4 samples were synthesized over 30, 60, 90 and $120 \mathrm{~min}$, respectively. The aqueous solutions of tin chloride $\mathrm{SnCl}_{2}(0.06 \mathrm{M})$ and sodium thiosulfate $\mathrm{Na}_{2} \mathrm{~S}_{2} \mathrm{O}_{3}(0.06 \mathrm{M})$ were used as $\mathrm{Sn}^{2+}$ and $\mathrm{S}^{2-}$ sources. In order to adjust the concentration of free $\mathrm{Sn}^{2+}$ cations, the complexing agent sodium citrate $\mathrm{Na}_{3}$ Cit was added into the reaction mixture. 
The $\mathrm{pH}$ value was maintained at $4.6 \pm 0.2$. All used chemical reagents were of analytical grade and used without further purification. After SnS deposition, the powders were taken out of the beaker, filtered, washed with distilled water and dried in air at ambient temperature.

Scanning electron microscopy (SEM) images were recorded on a scanning electron microscope JEOL-JSM LA 6390 at $20 \mathrm{kV}$. Energy dispersive X-ray (EDX) analysis was performed by using a JEOL JED-2300 detector. Xray powder diffraction (XRPD) patterns were collected on Shimadzu XRD-7000 automatic diffractometer $\left(\mathrm{Cu} K_{\alpha}\right.$ radiation) in the angle range $2 \theta$ of $5-80^{\circ}$ with step $0.03^{\circ}$ and an exposure time of $5 \mathrm{sec}$. The unit cell parameters of SnS were refined by Rietveld method using XRD data. The diffuse reflectance spectra of the SnS powders were recorded on a Shimadzu UV-3600 UV-VIS-NIR spectrophotometer using $\mathrm{BaSO}_{4}$ as a reference.

\subsection{Computational details}

The DFT calculations were performed using the SIESTA 4.0 implementation [16, 17]. Generalized Gradient Approximation (GGA) with the Perdew-Burke-Ernzerhof parametrization was used for description of exchangecorrelation potential. The core electrons were treated within the frozen core approximation, applying norm-conserving Troullier-Martins pseudopotentials. In all calculations, the double- $\zeta$ basis set was used. The k-point mesh was generated by the method of Monkhorst and Pack with a cutoff $15 \AA$ for the k-point sampling. The real-space grid used for the numeric integrations was set to correspond to the energy cutoff of $300 \mathrm{Ry}$. All calculations were performed using variable-cell and atomic position relaxations, with convergence criteria corresponding to the maximum residual stress of $0.1 \mathrm{GPa}$ for each component of the stress tensor, and the maximum residual force component of $0.01 \mathrm{eV} / \AA$.

\section{Results and discussion}

\subsection{Concentration regions of $\mathrm{SnS}$ solid phase formation by CBD}

The formation of SnS solid phase during CBD is a complex multistage process, which is based on the chemical reaction between a complex tin ion $\mathrm{SnCit}^{-}$and a sulfide ion $\mathrm{S}^{2-}$ released during the hydrolytic decomposition of $\mathrm{Na}_{2} \mathrm{~S}_{2} \mathrm{O}_{3}$. The chemical reaction can be represented as follows:

$$
\mathrm{SnCit}^{-}+\mathrm{Na}_{2} \mathrm{~S}_{2} \mathrm{O}_{3}+\mathrm{H}_{2} \mathrm{O}=\mathrm{SnS} \downarrow+\mathrm{Na}_{2} \mathrm{SO}_{4}+\mathrm{Cit}^{3-}+2 \mathrm{H}^{+} .
$$

The concentration regions for the formation of $\mathrm{SnS}$ and competitive hydroxide phase $\mathrm{Sn}(\mathrm{OH})_{2}$ as impurity were calculated for the " $\mathrm{SnCl}_{2}-\mathrm{Na}_{3} \mathrm{Cit}-\mathrm{Na}_{2} \mathrm{~S}_{2} \mathrm{O}_{3}$ " system (Fig. 1). The determination of the minimum concentration of metal salt $\mathrm{C}_{i n}$ required for solid phase either $\mathrm{SnS}(1)$ or $\mathrm{Sn}(\mathrm{OH})_{2}(2)$ depositions was carried out using the relations:

$$
\begin{gathered}
\mathrm{pC}_{i n}=\mathrm{pK}_{s p, S n S}-\mathrm{p} \alpha_{S n^{2+}}-\left(\frac{1}{2} \mathrm{pK}_{T S}-\mathrm{pH}+\frac{1}{2} \mathrm{p}\left[\mathrm{S}_{2} \mathrm{O}_{3}^{2-}\right]_{i n}\right)-\frac{0.86 \cdot \sigma \cdot V_{M}}{R \cdot T \cdot r_{c r}}, \\
\mathrm{pC}_{i n}=\mathrm{pK}_{s p, S n(O H)_{2}}-\mathrm{p} \alpha_{S n^{2+}}-2 \mathrm{pK}_{w}+2 \mathrm{pH},
\end{gathered}
$$

where $\mathrm{p}$ is the negative decimal logarithm; $\mathrm{K}_{s p, S n S}=6.92 \cdot 10^{-30}$ is the $\mathrm{SnS}$ solubility product; $\alpha_{S n}^{2+}$ is the fractional concentration of free $\mathrm{Sn}^{2+}$ ions; $\mathrm{K}_{T S}=1.99 \cdot 10^{-27}$ is the constant of $\mathrm{Na}_{2} \mathrm{~S}_{2} \mathrm{O}_{3}$ hydrolytic decomposition; $\left[\mathrm{Na}_{2} \mathrm{~S}_{2} \mathrm{O}_{3}\right]_{i n}$ is the initial $\mathrm{Na}_{2} \mathrm{~S}_{2} \mathrm{O}_{3}$ concentration in solution; $\sigma=1.75 \mathrm{~J} / \mathrm{m}^{2}$ is the SnS specific surface energy; $V_{M}=$ $28.88 \mathrm{~kg} / \mathrm{m}^{3}$ is the molar volume of synthesized SnS phase; $r_{c r}$ is the radius of the nucleus of critical size, $3.2 \mathrm{~nm} ; \mathrm{R}$ is the universal gas constant; $\mathrm{T}$ is the bath temperature; $\mathrm{pK}_{s p, S n(O H)_{2}}=6.31 \cdot 10^{-27}$ is the $\mathrm{Sn}(\mathrm{OH})_{2}$ solubility product; $\mathrm{K}_{w}$ is the $\mathrm{H}_{2} \mathrm{O}$ ionic product $[18,19]$.

As shown in Fig. 1, the presence of the $\mathrm{Na}_{3} \mathrm{Cit}$ ligand with the concentration of $0.15 \mathrm{M}$ may lead to the coprecipitation of $\mathrm{SnS}$ and $\mathrm{Sn}(\mathrm{OH})_{2}$ solid phases in the $\mathrm{pH}$ range from 6 to 12, while $\mathrm{C}_{i n}$ remains constant with a change of $\mathrm{Na}_{2} \mathrm{~S}_{2} \mathrm{O}_{3}$ concentration from 0.05 to $0.2 \mathrm{M}$. Thermodynamic calculations and the plotted dependence in three-dimensional coordinates " $\mathrm{pC}_{i n}-\left[\mathrm{Na}_{2} \mathrm{~S}_{2} \mathrm{O}_{3}\right]-\mathrm{pH}$ " showed that the acidic region $\mathrm{pH}=3-5$ is the most preferable for obtaining solid phase of $\mathrm{SnS}$.

\subsection{Phase identification}

The as-deposited layers were brownish black. The XRPD patterns of the SnS particles synthesized at different times are given in Fig. 2. The XRPD data showed the colloid particles to be tin(II) monosulfide SnS. The characteristic diffraction lines (111), (131) and (141) at $2 \theta$ positions $31.8^{\circ}, 38.4^{\circ}$ and $44.7^{\circ}$ match with the JCPDS reference database \# 00-039-0354, which is herzenbergite SnS or $\alpha$-SnS (orthorhombic; space group Pnma). The unit cell parameters were estimated to be $a=11.290(8) \AA, b=3.989(3) \AA, c=4.280$ (3) $\AA$; cell volume $\left.=192.8(3) \AA^{3}\right)$. No other impurities were found in the samples, indicating that the products are a pure SnS phase. The average crystalline sizes in the SnS1, SnS-2, SnS-3 and SnS-4 samples were determined as 19, 21, 23 and $20 \mathrm{~nm}$, respectively. The change of crystallite size with deposition time was insignificant. This can be attributed to a rapid growth of the SnS crystallites during the first 30 min of CBD process. A longer deposition time is inefficient to produce the larger particles. 


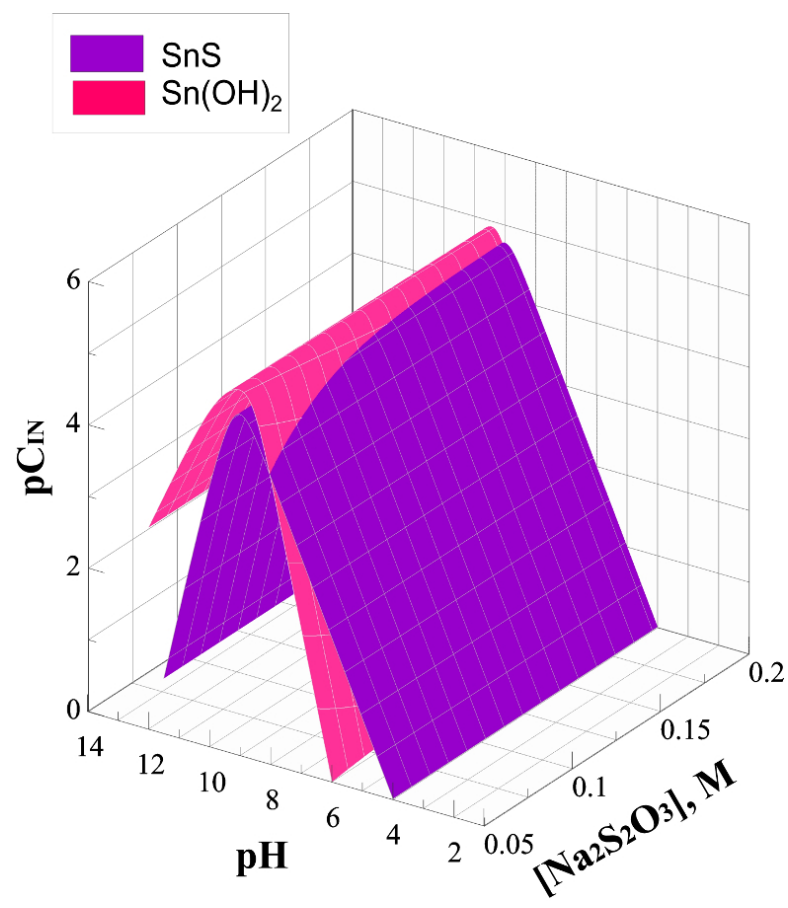

FIG. 1. Schematic diagram of concentration regions for formation of $\mathrm{SnS}$ and $\mathrm{Sn}(\mathrm{OH})_{2}$ solid phases. The calculations were carried out at different initial $\mathrm{pH}$ and $\mathrm{Na}_{2} \mathrm{~S}_{2} \mathrm{O}_{3}$ concentration for the " $\mathrm{SnCl}_{2}-\mathrm{Na}_{3} \mathrm{Cit}-\mathrm{Na}_{2} \mathrm{~S}_{2} \mathrm{O}_{3}$ " system at $T=298 \mathrm{~K}$

\subsection{Grain morphology and elemental composition}

The morphology and microstructure of SnS samples synthesized by CBD were visualized by scanning electron microscopy.The typical SEM micrograph shown in Fig. 3a corresponds to the powder SnS-1 synthesized during 30 min. Fig. 3 reveals that synthesized powders consist of nearly spherical particles of similar sizes $\sim 1 \mu \mathrm{m}$. Taking into account the XRPD data, the observed SnS colloid particles are polycrystals assembled of nanoparticles with the size of about $19 \mathrm{~nm}$. The EDX analysis (Fig. 3b) confirmed that particles consist of tin, sulfur and oxygen with an average content of $53 \pm 1,42 \pm 1$, and $5 \pm 1$ at. $\%$, respectively. The presence of oxygen might be due to water molecules adsorbed on the surface of $\mathrm{SnS}$ nanoparticles.

Therefore, the synthesized SnS colloid particles are found also to be Sn-rich. Despite of the initial reaction bath had an equimolar $\mathrm{Sn}^{2+} / \mathrm{S}_{2} \mathrm{O}_{3}^{2-}$ ratio, the disclosure of $\mathrm{Sn}$-rich particles suggest a partial reduction of $\mathrm{Sn}$ atoms embedded in $\mathrm{SnS}$ lattice through the reactions of $\mathrm{Sn}^{2+}+2 \mathrm{e}=\mathrm{Sn}^{0}(E=-0.140 \mathrm{~V})$ and $2 \mathrm{SO}_{4}^{2-}+10 \mathrm{H}^{+}+8 \mathrm{e}=\mathrm{S}_{2} \mathrm{O}_{3}^{2-}$ $+5 \mathrm{H}_{2} \mathrm{O}(E=0.29 \mathrm{~V})[17]$. Hence, it appeals that correct chemical formula for the synthesized colloid particles might be written here and thereafter as $\mathrm{Sn}_{1+x} \mathrm{~S}$ (Fig. 3).

\subsection{Optical properties}

The diffuse reflectance spectra of the SnS-1, SnS-2, SnS-3, and SnS-4 samples measured at 780-1800 nm wavelength range are presented in Fig. 4. The synthesized $\mathrm{Sn}_{1+x} \mathrm{~S}$ colloid particles do not absorb radiation with $\lambda=1450$ $1800 \mathrm{~nm}$; and the diffuse reflectance is approximately $100 \%$ in this spectral region. However, at $\lambda<1450 \mathrm{~nm}$ the significant decrease in the diffuse reflectance value takes place. The observed wide absorption band may be divided into two components at 780-880 $\mathrm{nm}$ and $880-1450 \mathrm{~nm}$, and the contribution of the latter increases with the deposition time.

The diffuse reflectance data were analyzed to determine the optical band gap energy $\left(E_{g}\right)$ of the samples. For a long time $\mathrm{SnS}$ had been considered as either direct and indirect allowed transition material until DFT calculations of electronic band structure of $\mathrm{SnS}$ in the bulk form as well as the in the bilayer and monolayer limit were performed [2022]. Calculations showed that the bulk and bilayer $\mathrm{SnS}$ have an indirect band gap, while for the monolayer possible direct transitions that are close in energy to the indirect gaps occur. Thus, the $E_{g}$ value was estimated taking into account the indirect allowed type of transitions. For this purpose, the Kubelka-Munk functions [23] were calculated 


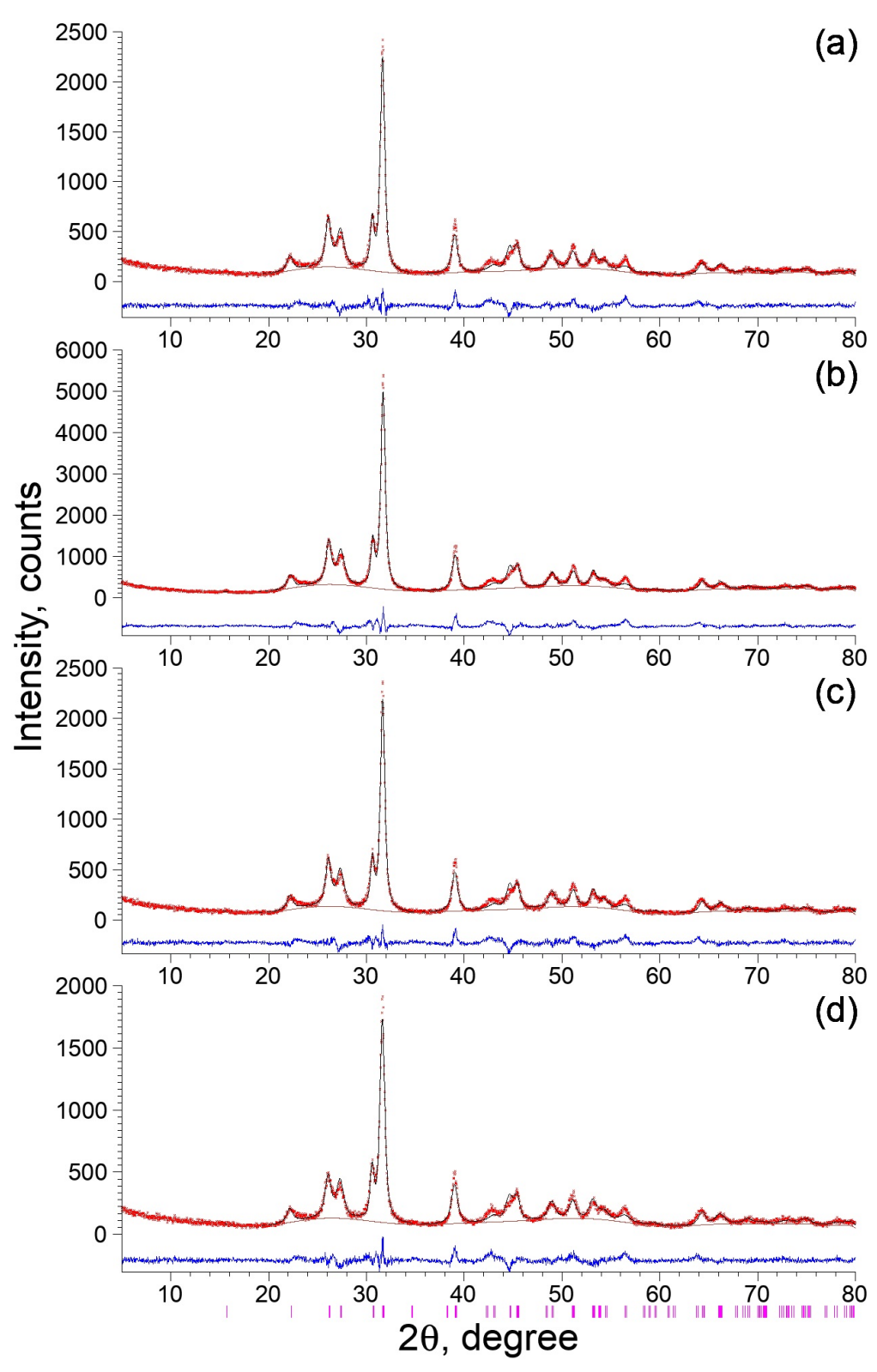

FIG. 2. The X-ray spectra of as-deposited SnS colloid particles obtained at different deposition times: (a) SnS-4 (120 min), (b) SnS-3 (90 min), (c) SnS-2 (60 min), (d) SnS-1 (30 min)

using equation (3) and then the appropriate dependences $[F(R) \mathrm{h} \nu]^{1 / 2}$ versus $\mathrm{h} \nu$ were plotted.

$$
F\left(R_{\infty}\right)=\frac{\left(1-R_{\infty}\right)^{2}}{2 R_{\infty}}=\frac{k}{s},
$$

where $F\left(R_{\infty}\right)$ is the diffuse reflectance of a sample relative to the reference, $k$ is the molar absorption coefficient, and $s$ is the scattering coefficient.

The results of the graphic determination of $E_{g}$ values are presented in the inset of Fig. 4. It has been revealed that all curves have linear parts at $1.41-1.44 \mathrm{eV}$. The found $E_{g}$ value is $1.34 \mathrm{eV}$ for the all studied samples [20]. This value is close to $E_{g}=1.24 \mathrm{eV}$ calculated for bulk $\mathrm{SnS}$ and is consistent with the reported experimental values of $1.05-1.47 \mathrm{eV}[7,21,24,25]$. The $E_{g}$ value of $\mathrm{SnS}$ may depend significantly on the degree of crystallinity, particle size and the stoichiometry of the samples. In a number of studies $[1,26]$ the change in the optical absorption edge of $\mathrm{SnS}$ was attributed to the presence of other phases like $\mathrm{SnO}_{2}\left(E_{g}=2.3-3.5 \mathrm{eV}\right), \mathrm{SnS}_{2}\left(E_{g}=2.44 \mathrm{eV}\right)$ and $\mathrm{Sn}_{2} \mathrm{~S}_{3}$ $\left(E_{g}=2.0 \mathrm{eV}\right)$. Since no regions of decreasing reflectance at these energies are observed, the possible formation of the 

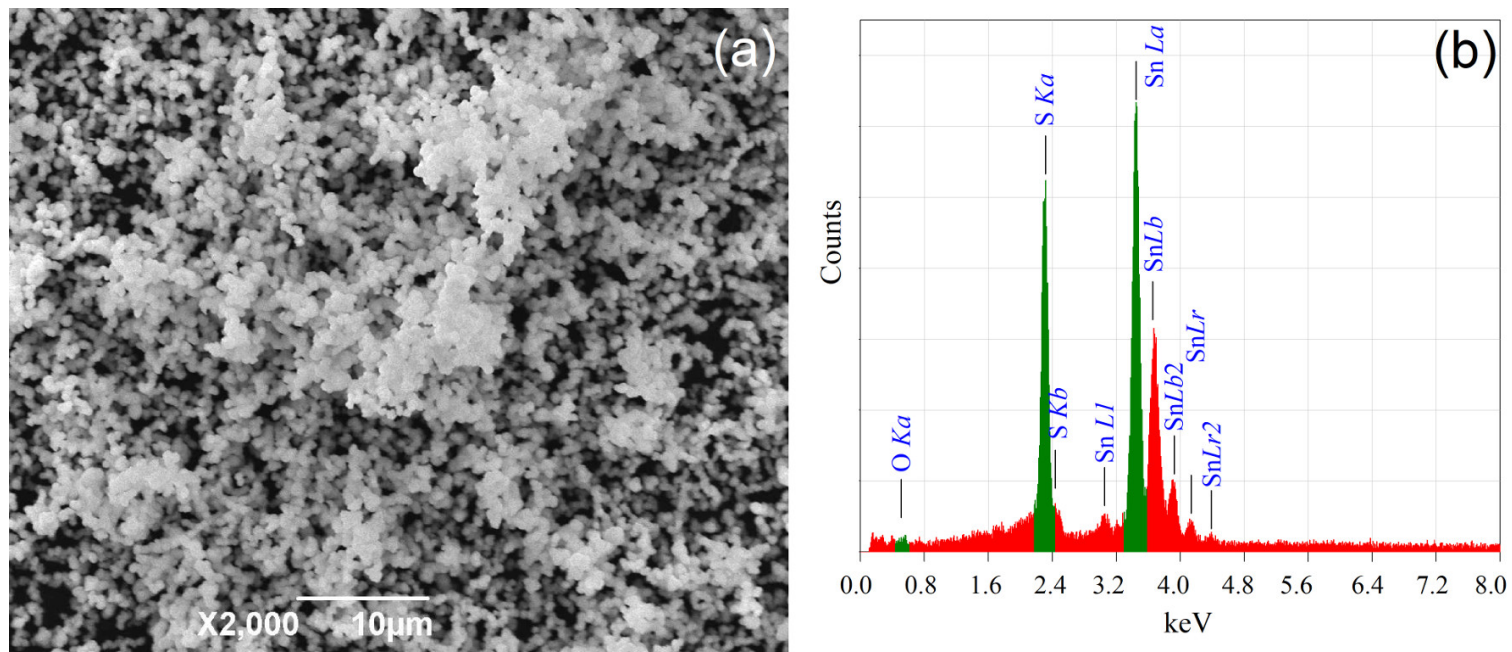

FIG. 3. The typical SEM image of $\operatorname{Sn}_{1+x} \mathrm{~S}$ colloid particles $(a)$; EDX analysis $(b)$ is presented for the SnS-1 sample synthesized during $30 \mathrm{~min}$

aforementioned impurity phases may be excluded from consideration. These results are well matched with the XRPD observations.

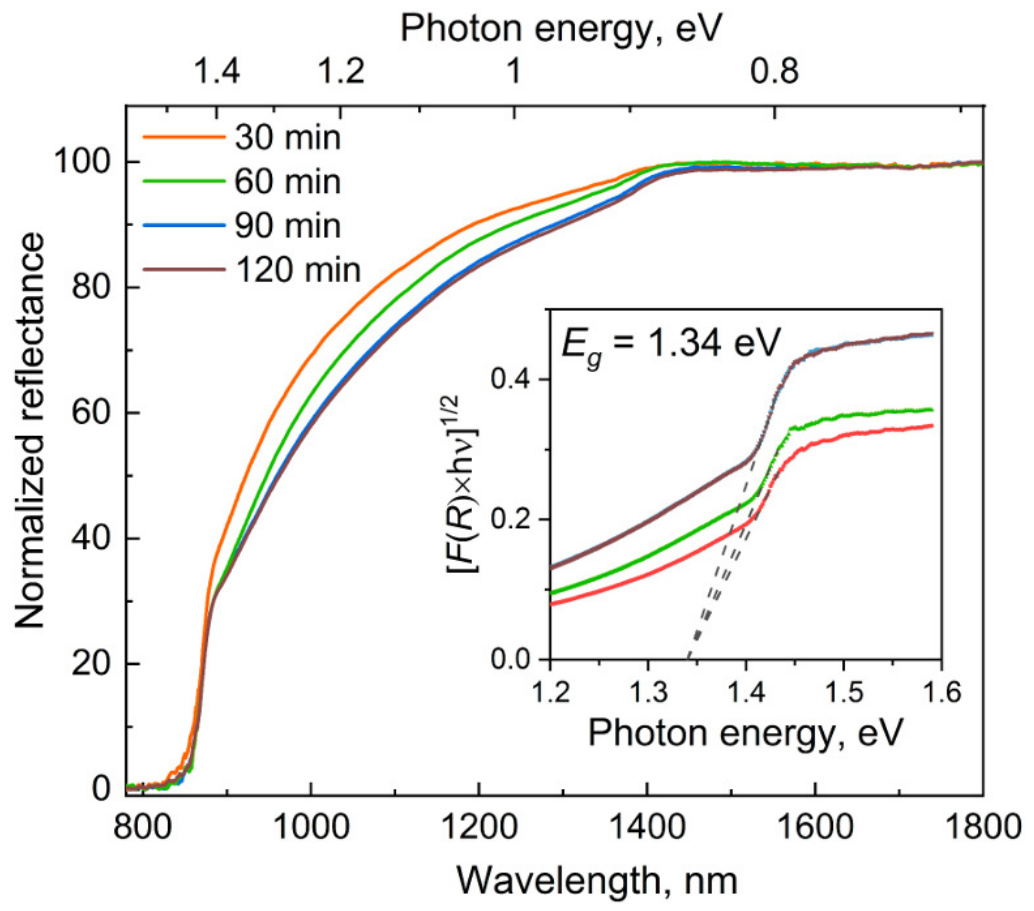

FIG. 4. Diffuse reflectance spectra for polycrystalline $\mathrm{Sn}_{1+x} \mathrm{~S}$ colloid particles obtained after different precipitation times. The inset shows the determination of the optical band gap energy

\subsection{DFT computational data}

A considerable 5-10\% Sn-excess has been registered in our SnS samples by means of EDX analysis, which surely exceeds experimental error in the detection and to ascribe the composition as $\mathrm{Sn}$-rich $\mathrm{SnS}-\mathrm{Sn}_{1+x} \mathrm{~S}$. No considerable distortion of the $\alpha$-SnS crystallattice has been established using XRPD method, which allows us to propose several simple scenarios for $\mathrm{Sn}$ surplus based on the same lattice: the most obvious S-vacancies at S-sublattice, Sn-atoms intercalated between $\mathrm{SnS}(001)$ layers and the non-trivial Sn-doping of S-sites.

Since the exact scenario cannot be definitively determined by means of the used characterization techniques, the DFT calculations have been employed preliminarily. The $1 \times 2 \times 2$ and $1 \times 3 \times 3$ supercells of $\alpha$-SnS were employed as 
parent models of $\mathrm{Sn}_{1+x} \mathrm{~S}$ compounds. The lattice parameters of pristine $\alpha$-SnS crystal can be found in fair agreement with experimental data as $a=11.42 \AA, b=4.05 \AA$ and $c=4.33 \AA$. A modification of the lattice by Sn surplus in amount of $x=0.05-0.07$ does lead to an essential modulation of the lattice parameters. The most prominent variation is observed for $c$-parameter: shrinking on $1.5 \%$ for $\mathrm{Sn}_{1+x} \mathrm{~S}$ with S-vacancies or with Sn-intercalants and expanding on $0.8 \%$ for $\mathrm{Sn}_{S}$-substituents. The $a$-parameter increases on $12.7 \%$ for $\mathrm{Sn}$-intercalated $\mathrm{Sn}_{1+x} \mathrm{~S}$, where Sn-intercalants adapt atypical double coordination and the Sn-S bond length equal to $2.78 \AA$. In the remaining cases, both $a$ - and $b$-parameters remain insensitive to a given $x$.

The relative stabilities of all three types of $\mathrm{Sn}_{1+x} \mathrm{~S}$ compounds have been estimated using the formation enthalpy $\Delta \mathrm{H}$ at $T=0 \mathrm{~K}$, calculated as the difference between the DFT total energies of a $\mathrm{Sn}_{1+x} \mathrm{~S}$ composition and of elements as $\beta$-Sn and cyclo- $\mathrm{S}_{8}$. In general, the data give proof for the thermodynamic destabilization of the SnS lattice upon any Sn-overdose, though, to different extents depending on $x$ (see Fig. 5). Namely, Sn-intercalates $\mathrm{Sn}_{1+x} \mathrm{~S}$ are characterized thermodynamically as the least stable, what should be an exclusion factor else in addition to the easily accessible Sn-intercalants for water solvent, hence, to enhanced reactivity of such $\mathrm{Sn}_{1+x} \mathrm{~S}$ in experiment. Sulfur-deficient $\mathrm{Sn}_{1+x} \mathrm{~S}$ compositions seem thermodynamically more stable, yet, unexpectedly losing in front of $\mathrm{Sn}_{S}$-substituted $\mathrm{Sn}_{1+x} \mathrm{~S}$. The latter compositions appear the most stable in all range of considered $\mathrm{x}$ up to $0.12-0.15$. Probably, their stability is promoted by similarity in local environment of Sn-atom placed at S-site of SnS lattice and that within the lattice of elemental $\beta$-Sn: both have a distorted octahedral Sn-environment and the Sn-Sn bond lengths as $3.09 \AA$ and 2.92$3.22 \AA$, respectively. A higher resistance to water oxidation could be also expected for such Sn-doping atoms due to preserved interplane $\mathrm{SnS}(100)$ distances as in pristine $\mathrm{SnS}$ and protection from SnS layers (i.e. from both basal and lateral directions).

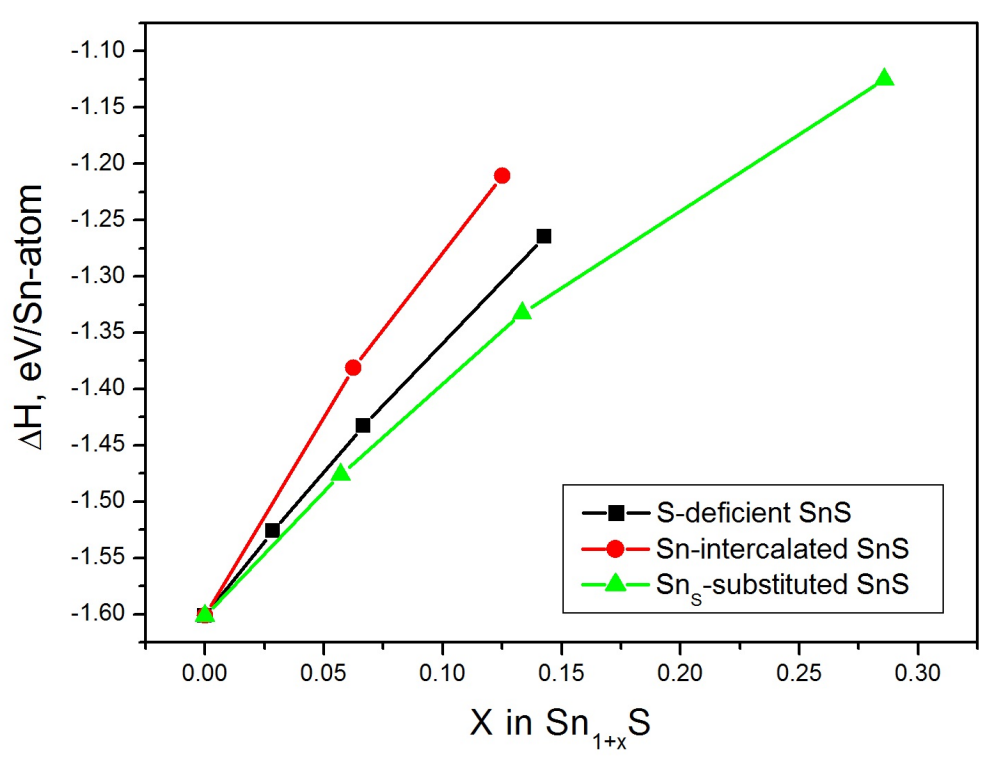

FIG. 5. Model formation enthalpies $\Delta \mathrm{H}$ (at $T=0 \mathrm{~K}$ ) for different Sn-rich $\mathrm{SnS}$ compositions based on $\alpha$-SnS latice: $\mathrm{SnS}$ with S-vacancies, $\mathrm{SnS}$ with intercalated $\mathrm{Sn}$-atoms and $\mathrm{SnS}$ with $\mathrm{Sn}$-doping into S-sites. DFT-GGA calculations

The calculated density of states (DOS) of pristine $\mathrm{SnS}$ and all types of $\mathrm{Sn}_{1+x} \mathrm{~S}$ are depicted in Fig. 6. Theoretically, $\mathrm{SnS}$ is a semiconductor with the band gap $0.77 \mathrm{eV}$. The band gaps are basically underestimated by classical DFT methods; however, this has no effect on their relative values and the character of DOS distribution. The bottom of the conduction band is dominated by Sn $5 p$-states. The top of the valence band composed of the S $3 p$-states with a considerable contribution of the Sn $5 s-$ and $\mathrm{Sn} 5 p$-states. The low-lying separate band in the range from -6 to $-8 \mathrm{eV}$ is contributed mostly from the valence Sn $5 s$-states. These main features of the DOS distribution are well preserved for the DOS profiles of $\mathrm{Sn}_{1+x} \mathrm{~S}$ compounds. However, the latter demonstrate distinct variety near the frontiers of the fundamental band gap. The least stable Sn-intercalated $\mathrm{Sn}_{1+x} \mathrm{~S}$ should be $\mathrm{n}$-type semiconductor with the main band gap $0.86 \mathrm{eV}$ and the donor impurity level at $0.13 \mathrm{eV}$ below the bottom of conduction band of SnS. S-deficient $\mathrm{Sn}_{1+x} \mathrm{~S}$ should be also $\mathrm{n}$-type semiconductor with the main band gap $0.76 \mathrm{eV}$ and the deep donor level at $0.33 \mathrm{eV}$ below the bottom of conduction band. $\mathrm{Sn}_{S}$-substituted $\mathrm{Sn}_{1+x} \mathrm{~S}$ demonstrates a more sophisticated DOS splitting near Fermi level: the main band gap $1.10 \mathrm{eV}$ hosts both donor and acceptor impurity levels at $0.59 \mathrm{eV}$ and $0.05 \mathrm{eV}$, respectively, below the bottom of conduction band. Additionally, the Sn $5 s$-band in the spectrum of this compound 
possesses a distinct splitting of the $\mathrm{Sn} 5 s$-levels at $0.23 \mathrm{eV}$ deep, serving as a good indicator for the possible detection of $\mathrm{Sn}_{S}$-impurities in ongoing experimental characterization.
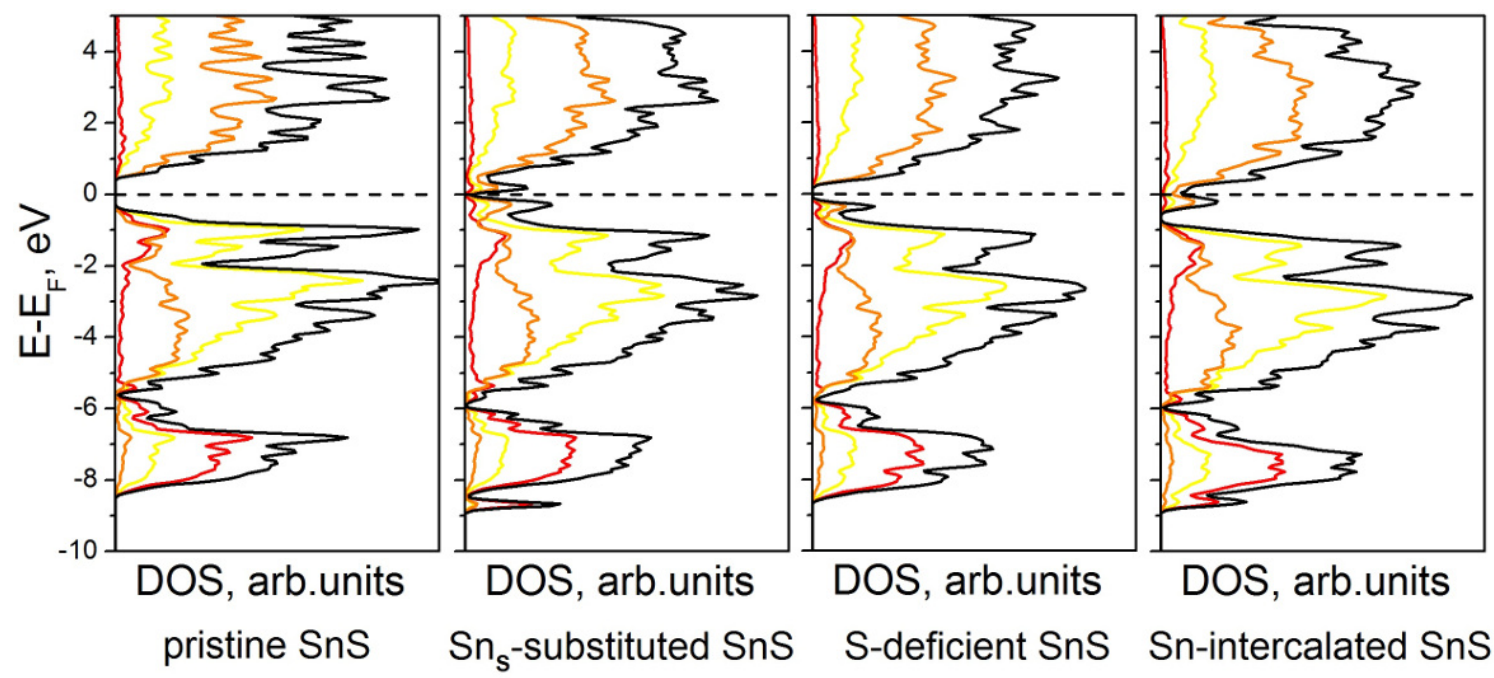

FIG. 6. Total and selected partial densities of states (DOS) for stoichiometric $\alpha$-SnS compound and different $\alpha-\mathrm{S}_{1+x} \mathrm{~S}$ compounds. Total and partial Sn $5 s-$, Sn $5 p$ - and S3p-DOS are drawn in black, red, orange and yellow, respectively. DFT-GGA calculations

\section{Conclusions}

In summary, tin (II) monosulfide colloids assembled of nanoparticles were synthesized in aqueous media at low temperatures by a CBD technique. The XRPD approves the formation of orthorhombic SnS phase with the optical band gap energy of $1.34 \mathrm{eV}$. Synthesized SnS nanoparticles with crystallite size of 19-23 nm tend to cluster in aqueous solution to form larger aggregates, i.e. colloid particles, with an average size $\sim 1 \mu \mathrm{m}$. The composition of SnS was found to be $\mathrm{Sn}$-rich due to the partial reduction of $\mathrm{Sn}^{2+}$ cations by anions $\mathrm{S}_{2} \mathrm{O}_{3}^{2-}$. The chemical formula for the synthesized colloid particles might be written as $\mathrm{Sn}_{1+x} \mathrm{~S}$. The DFT calculations demonstrated $\mathrm{Sn}_{S}$-substituted $\mathrm{Sn}_{1+x} \mathrm{~S}$ to be the most thermodynamically stable in all range of considered $\mathrm{x}$ up to $0.12-0.15$. Based on the present experimental and theoretical study, we suggest that CBD-deposited SnS has some potential as an inexpensive, earthabundant absorber material and photocatalyst for the degradation of organic compounds under sunlight. Furthermore, the resistivity of binary semiconductors is known to be strongly dependent on small deviations in stoichiometry. Snrich orthorhombic SnS may contribute to the superior electrochemical performance and may be applied for creating promising SnS-based anode materials for lithium-ion batteries [27]. Thus, our future work will focus on the electrochemical measurements with the aim of opening up a new opportunity for using CBD technique for the synthesis of $\mathrm{SnS}$ with regulated stoichiometry.

\section{Acknowledgements}

This work was performed in accordance with the scientific and research plans and state assignment of the ISSC UB RAS (theme AAAA-A19-119031890025-9) and by the Government of the Russian Federation (program 211, project No 02.A03.21.0006).

\section{References}

[1] Reddy K.T.R., Reddy N.K., Miles R.W. Photovoltaic properties of SnS based solar cells. Sol. Energy Mater. Sol. Cells, 2006,90, P. $3041-3046$.

[2] Noguchi H., Setiyadi A., Tanamura H., Nagatomo T., Omoto O. Characterization of vacuum-evaporated tin sulfide film for solar-cell materials. Sol. Energy Mater. Sol. Cells, 1994, 35(1-4), P. 325-331.

[3] Mathews N.R., Anaya H.B.M., Cortes-Jacome M.A., Angeles-Chavez C., Toledo-Antonio J. A. Tin sulfide thin films by pulse electrodeposition: structural, morphological, and optical properties. J. Electrochem. Soc., 2010, 157(3), P. H337-H341.

[4] Kabouche S., Bellal B., Louafi Y., Trari M. Synthesis and semiconducting properties of tin(II) sulfide: Application to photocatalytic degradation of Rhodamine B under sun light. Materials Chem. Phys., 2017, 195, P. 229-235.

[5] Gao W., Wu C., Cao M., Huang J., Wang L., Shen Y. Thickness tunable SnS nanosheets for photoelectrochemical water splitting. J. Alloys and Compounds, 2016, 688, P. 668-674. 
[6] Schneikart A., Schimper H.-J., Klein A., Jaegermann W. Efficiency limitations of thermally evaporated thin-film SnS solar cells. J. Phys. D: Appl. Phys., 2013, 46(30), P. 305109.

[7] Hartman K., Johnson J.L., Bertoni M.I., Recht D., Aziz M.J., Scarpulla M.A., Buonassisi T. SnS thin-films by RF sputtering at room temperature. Thin Solid Films, 2011, 519, P. 7421-7424.

[8] Wangperawong A., Herron S.M., Runser R.R., Haagglund C., Tanskanen J.T., Lee H., Clemens B.M., Bent S.F. Vapor transport deposition and epitaxy of orthorhombic $\mathrm{SnS}$ on glass and $\mathrm{NaCl}$ substrates. Appl. Phys. Lett., 2013, 103, P. 052105.

[9] Sinsermsuksakul P., Heo J., Noh W., Hock A.S., Gordon R.G. Atomic layer deposition of tin monosulfide thin films. Adv. Energy Mater, 2011, 1, P. 1116-1125.

[10] Ballipinar F., Rastogi A.C. Tin sulfide (SnS) semiconductor photo-absorber thin films for solar cells by vapor phase sulfurization of Sn metallic layers using organic sulfur source. J. Alloys and Compounds, 2017, 728, P. 179-188.

[11] Sajeesh T.H., Warrier A.R., Kartha C.S., Vijayakumar K.P. Optimization of parameters of chemical spray pyrolysis technique to get $\mathrm{n}$ and p-type layers of SnS. Thin Solid Films, 2010, 518, P. 4370-4374.

[12] Takeuchia K., Ichimuraa M., Araia E., Yamazaki Y. SnS thin films fabricated by pulsed and normal electrochemical deposition. Sol. Energy Mater. Sol. Cells, 2003, 75, P. 427-432.

[13] Pramanik P., Basu P.K., Biswas S. Preparation and characterization of chemically deposited tin(II) sulphide thin films. Thin Solid Films, 1987, 150(2-3), P. 269-276.

[14] Avelllaneda D., Nair M.T.S., Nair P.K. Polymorphic tin sulfide thin films of zinc blende and orthorhombic structures by chemical deposition. J. Electrochem. Soc., 2008, 155, P. D517-D525.

[15] Han Q., Wang M., Zhu J., Wu X., Lu L., Wang X. Great influence of a small amount of capping agents on the morphology of SnS particles using xanthate as precursor. J. Alloys and Compounds, 2011, 509(5), P. 2180-2185.

[16] Ordejon P., Artacho E., Soler J.M., Self-consistent order-N denisity-functional calculations for very large systems. Phys. Rev. B, 1996, 53, P. R10441.

[17] Soler J.M., Artacho E., Gale J.D., Garcia A., Junquera J., Ordejon P., Sanchez-Portal D. The SIESTA method for ab initio order-N materials simulation. J. Phys. Condens. Matter, 2002, 14, P. 2745-2780.

[18] Markov V.F., Maskaeva L.N., Ivanov P.N. Hydrochemical deposition of metal sulfide thin solid films: modeling and experiment. Ekaterinburg: UrB RAS, 2006, 217 p. (in Russian)

[19] Lurie Ju.Ju. Handbook of Analytical Chemistry. Mir Publishers, 1975, 488 p.

[20] Gomes L.C., Carvalho A. Phosphorene analogues: isoelectronic two-dimensional group-IV monochalcogenides with orthorhombic structure. Phys. Rev., 2015, B92(8), P. 085406.

[21] Titova L.V., Fregoso B.M., Grimm R.L. Chapter 5: Group-IV monochalcogenides GeS, GeSe, SnS, SnSe, in book Chalcogenide: From 3D to 2D and Beyond. Woodhead Publishing Series in Electronic and Optical Materials, 2020, P. 119-151.

[22] Popov I.S., Kozhevnikova N.S., Enyashin A.N. Quantum-chemical study of structural and electronic properties of a new tin monosulfide polymorph $\pi$-SnS. Doklady Physical Chemistry, 2017, 472(2), P. 23-26.

[23] Kubelka P., Munk-Aussig F. Ein Beitrag zur Optik der. Farbanstriche. Z. Tech. Physik, 1931, 12, P. 593-601.

[24] Reddy N.K., Hahn Y.B. Temperature-dependent structural and optical properties of SnS films. J. Appl. Phys., 2007, 101(9), P. 093522.

[25] Parenteau M., Carlone C. Influence of temperature and pressure on the electronic transitions in SnS and SnSe semiconductors. Phys. Rev. B, 1990, 41(8), P. 5227-5234.

[26] Lopez S., Granados S., Ortiz A. Semicond. Spray pyrolysis deposition of $\mathrm{Sn}_{2} \mathrm{~S}_{3}$ thin films. Sci. Technol., 1996, 11(3), P. $433-436$.

[27] Zhang J., Cao D.,Wu Y., Cheng X., Kang W., Xu J. Phase transformation and sulfur vacancy modulation of 2D layered tin sulfide nanoplates as highly durable anodes for pseudocapacitive lithium storage. Chemical Engineering J., 2020, 392, P. 123722(1-10). 